This article is licensed under the Creative Commons Attribution-NonCommercial 4.0 International License (CC BY-NC) (http://www.karger.com/Services/OpenAccessLicense). Usage and distribution for commercial purposes requires written permission.

\title{
Late Cutaneous Metastasis Originating from Gastric Cancer with Synchronous Metastasis
}

\author{
Ryota Koyama Yoshiaki Maeda Nozomi Minagawa Toshiki Shinohara \\ Tomonori Hamada \\ Department of Gastrointestinal Surgery, Hokkaido Cancer Center, Sapporo, Japan
}

\section{Keywords}

Gastric cancer · Late cutaneous metastasis · Tumor dormancy

\begin{abstract}
An 89-year-old man was diagnosed with late cutaneous metastasis in the right axilla 6 years after undergoing a surgery for gastric cancer with synchronous cutaneous metastasis in the same site. The patient became aware of small reddish nodules in the right axilla, and computed tomography imaging showed an irregular thickening of the right axillary skin. No other sign of recurrence was observed. By en-bloc resection, the nodules were diagnosed as late cutaneous metastasis from gastric cancer. The patient received no additional postoperative chemo- or radiotherapy and was only carefully observed. Cutaneous metastases from gastric cancer have a high recurrence rate even if total resection with no residual cancer is achieved. Therefore, meticulous follow-up, including routine visual inspection, is required for the early detection of late cutaneous metastases.

(C) 2019 The Author(s)

Published by S. Karger AG, Basel
\end{abstract}




\section{Case Reports in Gastroenterology} \begin{tabular}{l|l} 
Case Rep Gastroenterol 2019;13:95-101 \\
\hline DOI: 10.1159/000497099 & $\begin{array}{l}\text { @ 2019 The Author(s). Published by S. Karger AG, Basel } \\
\text { www.karger.com/crg }\end{array}$
\end{tabular}

Koyama et al.: Late Cutaneous Metastasis Originating from Gastric Cancer with Synchronous Metastasis

\section{Introduction}

Advanced gastric cancer commonly causes metastasis to the peritoneal cavity, lymph nodes, liver, and lung, with the skin being a very rare site. Cutaneous metastasis is generally a late clinical presentation indicating systemic dissemination with poor prognosis. Generally, cutaneous metastasis from gastric cancer indicates inoperable state, and only a few cases of resection with no residual tumor have so far been reported. We report an extremely unusual case of late cutaneous metastasis in the right axilla originating from primary gastric cancer with a solitary synchronous cutaneous metastasis in the same part of the body.

\section{Case Presentation}

An 89-year-old man underwent distal gastrectomy with lymph node dissection and concurrent resection of metastasis in the right axilla 6 years ago. The pathological diagnosis was T3N0M1 (skin), pStage IV. Immunohistochemistry of both the gastric cancer and right axillary metastasis tissues showed CK7 positivity, CK20 negativity, CDX-2 negativity, and a final diagnosis of solitary synchronous cutaneous metastasis originating from gastric cancer was made. The primary and metastatic tumors were resected with negative surgical margins. As adjuvant chemotherapy, seven courses of S-1 were administered. The patient was regularly followed up with laboratory tests and imaging studies with no signs of recurrence. After 6 years, the patient became aware of small, slowly growing reddish nodules on the scar of the primary surgery in his right axilla (Fig. 1). On physical examination at the first visit, the vital signs were within normal limits, and the abdomen was soft and flat without tenderness, or rebound tenderness. The serum level of carcinoembryonic antigen was normal ( $4.8 \mathrm{ng} / \mathrm{mL})$, and carbohydrate antigen 19-9 was slightly elevated (44 U/mL). Other laboratory data showed no abnormalities. Ultrasonography showed merged low echoic masses with a maximum size of $7 \mathrm{~mm}$ with high pulsation. Computed tomography revealed irregular thickening of the right axillary skin (Fig. 2), and no other signs of recurrence including lungs and the abdomen were observed. Based on these findings, a diagnosis of late cutaneous metastasis from gastric cancer was made. For diagnosis confirmation and treatment, resection as a total biopsy was performed. The operation was performed with the local anesthesia without any complication. Histopathological examination revealed moderately to poorly differentiated adenocarcinoma with proliferation of atypical epithelium forming ductal and nest-like structures, and immunohistochemistry showed CK7 positivity, CK20 negativity, CDX-2 negativity (Fig. 3). The histological appearance and the immunohistochemistry were identical to the tissues of the gastric carcinoma and the synchronous cutaneous metastasis resected 6 years ago (Fig. 4); therefore, a diagnosis of solitary late cutaneous metastasis from gastric cancer was made. Considering his age and the absence of recurrences elsewhere, the patient received no additional treatment postoperatively and was only observed. 


\section{Case Reports in Gastroenterology}

Case Rep Gastroenterol 2019;13:95-101

DOI: 10.1159/000497099

(C) 2019 www.karger.com/crg

Koyama et al.: Late Cutaneous Metastasis Originating from Gastric Cancer with Synchronous Metastasis

\section{Discussion}

Cutaneous metastasis is rare, with an overall incidence of $5 \%$ of all visceral malignancies [1]. The most common primary site of cutaneous metastasis is breast cancer, and gastric cancer is very rare. Cutaneous metastasis from gastric cancer is often considered to be incurable in the late stage of advanced cancer. Late cutaneous metastases are defined as those occurring late after resection of the primary tumor [2]. Previous reports showed that 7-9\% of cutaneous metastases were late recurrences $[3,4]$.

Cutaneous metastasis commonly originates from breast, lung, colon, oral cavity, kidney, or ovarian malignancies $[5,6]$. Among these organs, cutaneous metastases from breast cancer are characteristically confined to the skin in one-third of the patients, suggesting that it is not a clinical presentation of disseminated disease [5].

The sites of cutaneous metastasis of gastric cancer are mostly the chest and abdomen due to their proximity from the origin of malignancy. Surgical scars are also common sites due to iatrogenic implantation [6].

We searched the PubMed database for reports of cases undergoing surgical resection of cutaneous metastasis from gastric cancer using with the keywords "gastric cancer," "resection," and "cutaneous metastasis." Six cases were found (Table 1) [7-12]. Five out of 7 patients, including ours, lived longer than 3 years after resection of the cutaneous metastasis, indicating a benefit from the surgical intervention. When the primary lesion is well controlled and the cutaneous metastasis is completely resectable, good prognosis might be expected. However, if the cutaneous metastasis is part of the disseminated lesions, resection of cutaneous metastasis is not recommended unless they are adversely affecting the patient's quality of life.

Mechanistically, cutaneous metastasis occurs by hematogenous or lymphatic spread, direct invasion of primary cancer, and intraoperative implantation of cancer cells into the skin. In our case, the solitary synchronous cutaneous metastasis in the right axilla can be explained by hematogenous spread from the primary gastric cancer. However, the explanation of the preferential affection of the right axilla remains unknown. As for the late cutaneous recurrence, intraoperative implantation is the most likely explanation.

Stephen Paget described the "seed and soil theory" [13], which explains the metastatic process to certain organs. This theory might be applied to our case as follows; the gastric cancer cells ("seed") release humoral factors into the systemic circulation to prepare the pre-metastatic niche ("soil," in this case, right axillary skin), which allows for colonization and survival of gastric cancer cells. In the organ-selective phase, chemokines and their receptors have been shown to play a pivotal role.

The cause of relapse after a long period of time might be related to tumor dormancy [14]. Tumor dormancy is characterized by cell cycle arrest induced by incompatibilities between immune evasion of cancer cells due to cancer cells and tumor microenvironment. The long period of dormancy may be due to a weakened immune system owing to old age. Moreover, the history of adjuvant chemotherapy (S-1) after the initial surgery might have helped to establish tumor dormancy and extended the relapse-free period [15].

Our case is extremely unusual in two points. First, the initial presentation was primary gastric cancer and a solitary cutaneous metastasis to the right axilla. Second, both synchronous and metachronous solitary cutaneous metastasis occurred in the same site in the same 
patient. We concluded that the first metastasis to the right axilla was hematogenous, and that the recurrence at the same site was due to the cancer cell implantation.

In general, cutaneous metastasis from gastric cancer is considered to be an end-stage presentation with poor prognosis. However, if the metastasis is resectable, and in the absence of metastases elsewhere, surgical resection could be offered as a treatment option. Moreover, patients with synchronous cutaneous metastasis must be meticulously followed up given the high risk of recurrence.

\section{Statement of Ethics}

The authors have no ethical conflicts to disclose.

\section{Disclosure Statement}

The authors have no conflicts of interest to declare.

\section{References}

1 Krathen RA, Orengo IF, Rosen T. Cutaneous metastasis: a meta-analysis of data. South Med J. 2003 Feb;96(2):164-7.

2 Willis RA. The spread of tumours in the human body, Delayed growth of metastatic tumours. 3rd ed. London: Butterworths; 1973. pp. 79-82.

3 Mehregan AH. Metastatic carcinoma to the skin. Dermatologica. 1961 Nov;123(5):311-25.

4 Brownstein MH, Helwig EB. Spread of tumors to the skin. Arch Dermatol. 1973 Jan;107(1):80-6.

5 Hu SC, Chen GS, Lu YW, Wu CS, Lan CC. Cutaneous metastases from different internal malignancies: a clinical and prognostic appraisal. J Eur Acad Dermatol Venereol. 2008 Jun;22(6):735-40.

6 Schwartz RA. Cutaneous metastatic disease. J Am Acad Dermatol. 1995 Aug;33(2 Pt 1):161-82.

7 Früh M, Ruhstaller T, Neuweiler J, Cerny T. Resection of skin metastases from gastric carcinoma with longterm follow-up: an unusual clinical presentation. Onkologie. 2005 Jan;28(1):38-40.

8 Karayiannakis AJ, Bolanaki H, Tsalikidis C, Simopoulos C. Cutaneous metastasis at a surgical drain site after gastric cancer resection. Case Rep Oncol. 2010 Sep;3(3):495-7.

9 Cesaretti M, Malerba M, Basso V, Boccardo C, Santoni R, D’Alessandro G, et al. Cutaneous metastasis from primary gastric cancer: a case report and review of the literature. Cutis. 2014 Apr;93(4):E9-13.

10 Katayama T, Ishii T, Tono T, Okubo Y, Shinozaki K, Kawasaki Y, et al: Gastric cancer diagnosed with metastasis of navel (Sister Mary Joseph's nodule) - A case report [in Japanese]. Gan To Kagaku Ryoho. 2016 Nov;43(12):1905-1907.

11 Morita J, Aoyama T, Amano S, Maezawa Y, Sawazaki S, Numata M, et al. A case of long-term survival of cutaneous metastasis from primary gastric cancer [in Japanese]. Gan To Kagaku Ryoho. 2017 Nov;44(12):1393-5.

12 Namikawa T, Munekage E, Munekage M, Maeda H, Yatabe T, Kitagawa H, et al. Subcutaneous metastasis arising from gastric cancer: A case report. Mol Clin Oncol. 2017 Apr;6(4):515-6.

13 Paget S. The distribution of secondary growths in cancer of the breast. Lancet. 1889;133(3421):571-3.

14 Giancotti FG. Mechanisms governing metastatic dormancy and reactivation. Cell. 2013 Nov;155(4):750-64.

15 Páez D, Labonte MJ, Bohanes P, Zhang W, Benhanim L, Ning Y, et al. Cancer dormancy: a model of early dissemination and late cancer recurrence. Clin Cancer Res. 2012 Feb;18(3):645-53. 


\section{Case Reports in Gastroenterology}

Case Rep Gastroenterol 2019;13:95-101

(C) 2019 The Author(s). Published by S. Karger AG, Basel www.karger.com/crg

Koyama et al.: Late Cutaneous Metastasis Originating from Gastric Cancer with Synchronous Metastasis

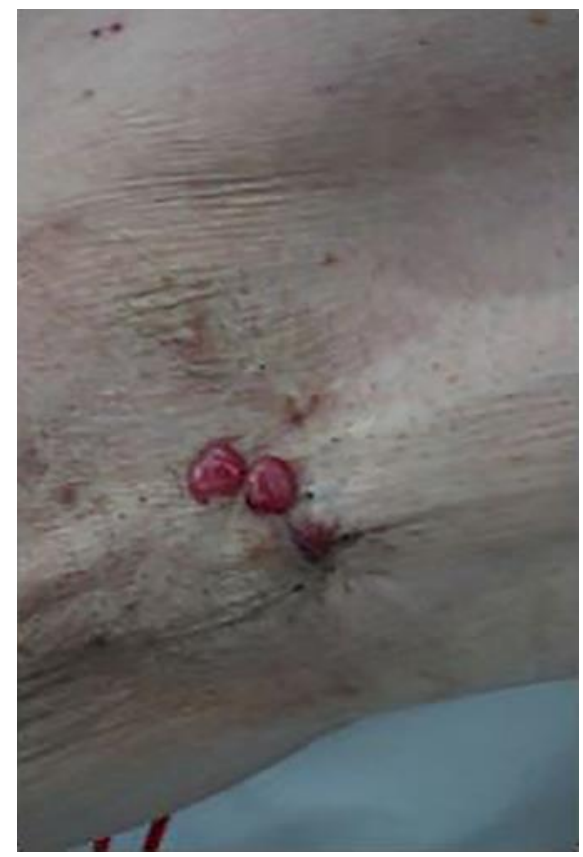

Fig. 1. The right axillary skin appearance. Small reddish nodules were noted at the same site as the synchronous cutaneous metastasis.

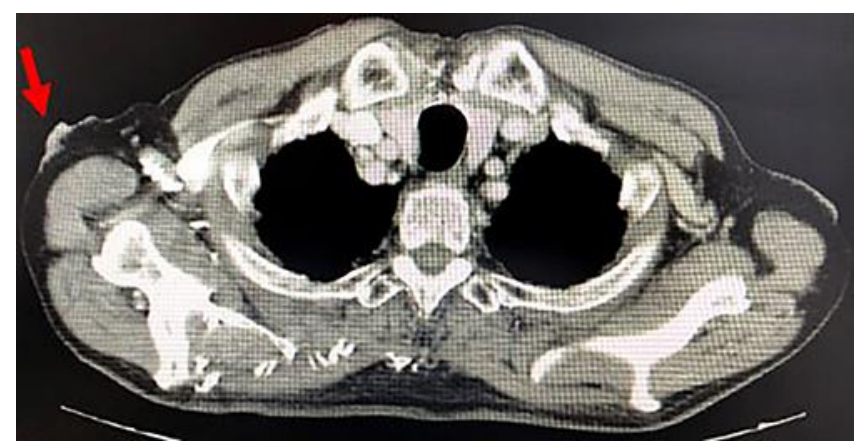

Fig. 2. Computed tomography imaging. Irregular thickening of the right axillary skin was noted. 


\section{Case Reports in Gastroenterology}

Case Rep Gastroenterol 2019;13:95-101
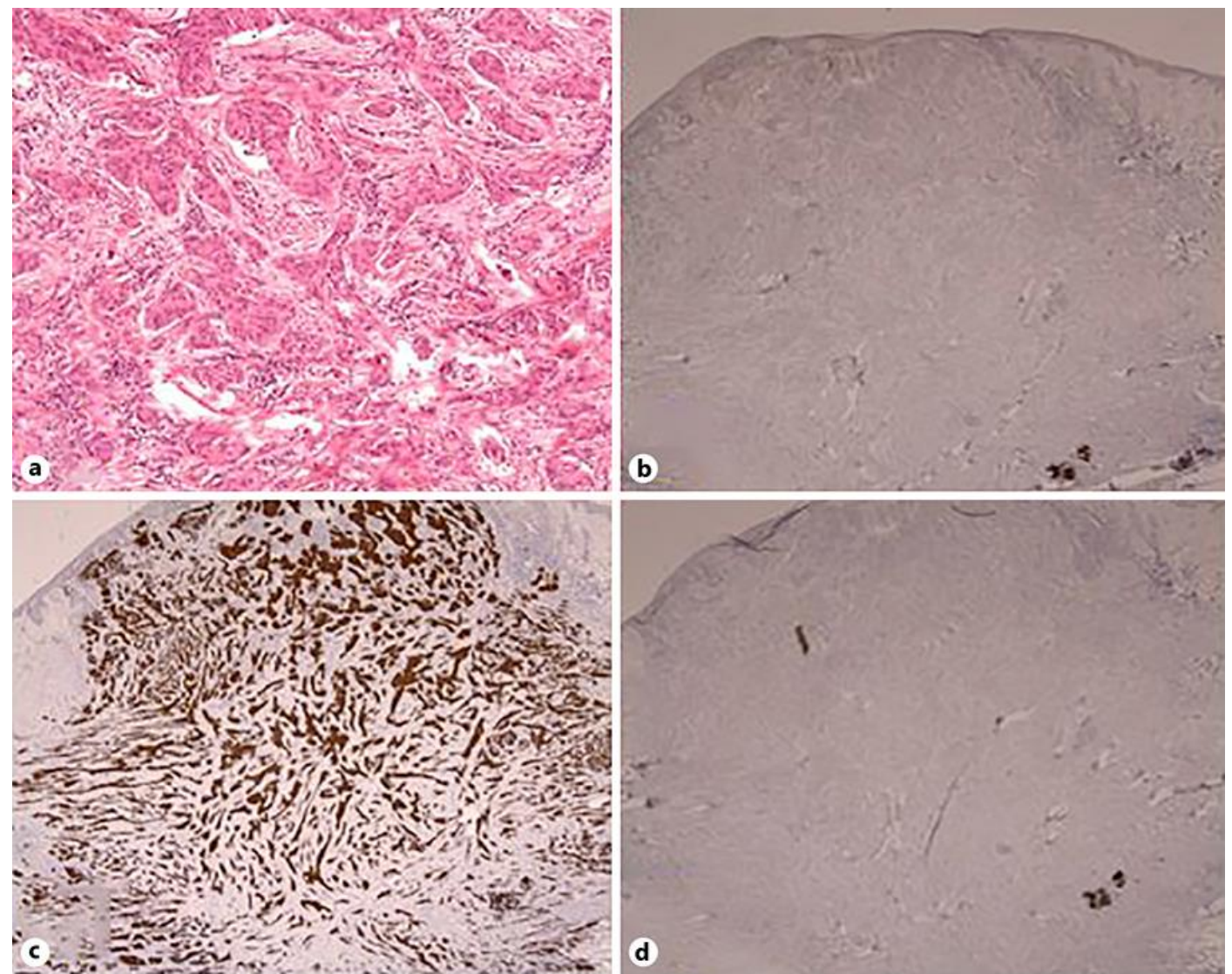

Fig. 3. Histopathological findings of the metachronous cutaneous metastasis of the right axillary skin. a Moderately to poorly differentiated adenocarcinoma with proliferation of atypical epithelium forming ductal and nest-like structure, showing similarity to the tissues of gastric cancer resected 6 years ago. HE. $\times 100$. b-d Immunohistochemical staining was positive for CK7 (c), and negative for CDX-2 (b) and CK20 (d). 


\section{Case Reports in Gastroenterology}

Case Rep Gastroenterol 2019;13:95-101
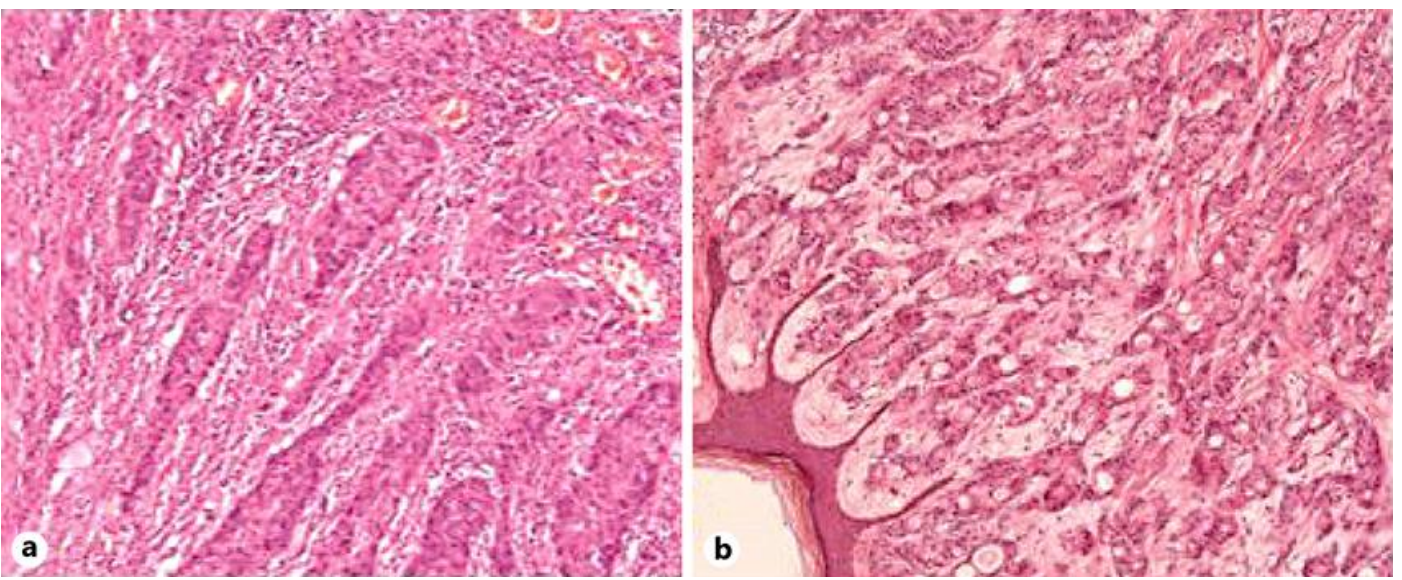

Fig. 4. Histopathological findings of the gastric cancer (a) and the synchronous cutaneous metastasis of the right axillary skin (b) resected 6 years ago. a, b Moderately to poorly differentiated adenocarcinoma was observed. Immunohistochemical staining was positive for CK7 and negative for CDX-2 and CK20 (not shown). HE. $\times 100$.

Table 1. Cases of resected cutaneous metastasis from gastric cancer

\begin{tabular}{|c|c|c|c|c|c|c|c|}
\hline Year & First author [Ref.] & $\begin{array}{l}\text { Age/ } \\
\text { sex }\end{array}$ & $\begin{array}{l}\text { Metastasis } \\
\text { except skin }\end{array}$ & $\begin{array}{l}\text { Metastatic site } \\
\text { of the body }\end{array}$ & $\begin{array}{l}\text { Synchronous/ } \\
\text { metachronous } \\
\text { (time from } \\
\text { primary surgery) }\end{array}$ & $\begin{array}{l}\text { Adjuvant chemother- } \\
\text { apy for gastric cancer }\end{array}$ & $\begin{array}{l}\text { Prognosis after } \\
\text { resection of cuta- } \\
\text { neous metastasis }\end{array}$ \\
\hline 2005 & Früh [7] & 60 & none & head, thigh & metachronous (2y) & no description & $>7.5$ years \\
\hline 2010 & Karayiannakis [8] & $76 \mathrm{M}$ & none & drain site & metachronous (4 m) & irinotecan, L-OHP & 1 month \\
\hline 2014 & Cesaretti [9] & $60 \mathrm{M}$ & not described & chest wall & metachronous (6y) & epirubicin, CDDP, 5-FU & $>40$ months \\
\hline 2016 & Katayama [10] & $60 \mathrm{~F}$ & peritoneum & umbilicus & synchronous & $\begin{array}{l}\text { CDDP, capecitabine, } \\
\text { trastuzumab }\end{array}$ & $>5$ years \\
\hline 2017 & Morita [11] & $65 \mathrm{~F}$ & none & umbilicus & metachronous (5y) & no description & $>3$ years \\
\hline 2017 & Namikawa [12] & $59 \mathrm{M}$ & liver, bone & chest wall & synchronous & S-1, L-OHP & 6 months \\
\hline 2018 & Our study & $89 \mathrm{M}$ & none & right axilla & $\begin{array}{l}\text { synchronous/ } \\
\text { metachronous (6y) }\end{array}$ & S-1 & $\begin{array}{l}>6 \text { years (from } \\
\text { the first surgery) }\end{array}$ \\
\hline
\end{tabular}

